\title{
Mycotoxins Contaminant in Kelp: A Neglected Dietary Exposure Pathway
}

\author{
Yanshen Li ${ }^{1, *}$, Mingxue Sun ${ }^{1}$, Xin Mao ${ }^{1}$, Yanli You ${ }^{1}$, Yonglin Gao ${ }^{1}$, Jianrong Yang ${ }^{1}$ \\ and Yongning $\mathrm{Wu}^{2,3, *}$ \\ 1 Marine Product Quality and Safety Inspection Key Laboratory in Shandong Province, College of \\ Life Science, Yantai University, Yantai 264005, China; Sunmingxuee@outlook.com (M.S.); \\ maoxin103820@ytu.edu.cn (X.M.) Youyanli@ytu.edu.cn (Y.Y.); gaoyonglin@ytu.edu.cn (Y.G.); \\ yangjianrong@ytu.edu.cn (J.Y.) \\ 2 NHC Key Lab of Food Safety Risk Assessment, China National Center for Food Safety Risk Assessment, \\ Beijing 100022, China \\ 3 College of Food Science and Engineering, Shandong Agricultural University, Tai'an 271018, China \\ * Correspondence: liyanshen@ytu.edu.cn (Y.L.); wuyongning@cfsa.net.cn (Y.W.); Tel.: +86-0535-690-2638 (Y.L.); \\ $+86-010-521-65518$ (Y.W.)
}

Received: 8 October 2018; Accepted: 12 November 2018; Published: 19 November 2018

\begin{abstract}
In order to investigated current occurrence of major mycotoxins in dietary kelp in Shandong Province in Northern China, a reliable, sensitive, and rapid liquid chromatography tandem mass spectrometry (LC-MS/MS) method was developed and validated for simultaneous determination of the 7 most frequent mycotoxins, including 3-acetoxy deoxynivalenol (3AcDON), 15-acetoxy deoxynivalenol (15AcDON), Deoxynivalenol (DON), Fusarenon-X (F-X), Nivalenol (NIV), T-2 toxin (T-2), and Zearalenone (ZEA). Based on optimized pretreatment and chromatographic and mass spectrometry conditions, these target analytes could be monitored with mean recoveries from $72.59 \sim 107.34 \%$, with intra-day RSD $<9.21 \%$, inter-day RSD $<9.09 \%$, LOD $<5.55 \mu \mathrm{g} \mathrm{kg}^{-1}$, and LOQ $<18.5 \mu \mathrm{g} \mathrm{kg}^{-1}$. Approximately $43 \mathrm{kelp}$ samples were detected, 3AcDON/15AcDON ranged from 15.3 to $162.5 \mu \mathrm{g} \mathrm{kg}^{-1}$ with positive rate of $86 \%$ in Shandong Province in Northern China. Considering there were no related investigations about mycotoxin contamination in kelp, the high contamination rate of $3 \mathrm{AcDON} / 15 \mathrm{AcDON}$ in kelp showed a neglected mycotoxin exposure pathway, which might lead to high dietary exposure risk to consumers.
\end{abstract}

Keywords: LC-MS/MS; mycotoxins; dietary exposure risk; kelp; Northern China

Key Contribution: We developed a sonication assistant and acidulated extraction coupled LC-MS/MS method for major mycotoxins detection in kelp. Unexpected mycotoxin dietary exposure pathway in kelp was first reported, and masked mycotoxin of 3AcDON/15AcDON were detected in kelp in Shandong in Northern China (15.3 162.5 $\left.\mu \mathrm{g} \mathrm{kg}^{-1}\right)$.

\section{Introduction}

Mycotoxins are mainly produced by filamentous fungi in a complex matrix [1,2]. Mycotoxins can contaminate different agricultural commodities and they are mainly detected in cereals, such as barley, wheat, maize, and even fruit and related products [3-6]. Considering the severe toxicity, the presence of mycotoxins in foods could induce a high potential risk to human health, such as endocrine disorders, immunosuppression, teratogenic, carcinogenic and mutagenic effects, and so on $[7,8]$. In recent decades, due to the high frequency of contamination and widespread occurrence, mycotoxins have increasingly attracted attention worldwide. 
It is well known the kelps are major keystone species which remain deep rooted in the marine environment [9]. Also, there are ample minerals and nutrients in kelps, which make them highly bioactive for human beings. Kelps usually grow on the bottom of the sea. They contain fiber, protein, beta carotene, amino acids, enzymes and chlorophyll, leading to the high quality in foods. In addition, there are also phosphorus, iron, sodium, potassium, calcium, magnesium, and other minerals in kelp [10]. Considering the similar components as cereals with protein and polysaccharose, fungi may also grow in kelps during the storage stage. Therefore, mycotoxins might also occur in kelps and related food and feeds. To the best of our knowledge, there is scarcely any information regarding the presence of mycotoxins in kelps. Reports about the transformation and generation of mycotoxins in kelps have also not been presented. In order to control mycotoxins in foods and feeds, the first and most important step is to develop sensitive and reliable methods for mycotoxin monitoring.

In the last decades, there have been numerous studies on mycotoxin detection with different chromatographic equipment, such as High Performance Liquid Chromatography (HPLC) [11-13], Liquid Chromatography Tandem Mass Spectrometry (LC-MS/MS) [14-16]), Gas Chromatography (GC) $[17,18]$, Gas Chromatography Tandem Mass Spectrometry (GC-MS) [19-22], and so on. Antibody-based immunoassays were also applied for mycotoxin detection with advantages of simplicity, low-cost and high throughput. These immunoassays mainly include enzyme linked immunosorbent assay (ELISA) [23-25], fluorescence polarization immunoassay (FPIA) [26-28], surface plasmon resonance (SPR) [29-32], flow cytometric microsphere immunoassay [33-35], and rapid strip tests [36,37]. However, these methods mainly focused on cereal matrix and related products. As far as we know, there are very few reports on the detection of these targets in marine-derived products, especially kelps. Considering the high frequency of contamination of mycotoxins in cereals, exposure to kelps with similar components as cereals should be taken seriously. For the exposure investigation, the first and most important step is to develop a reliable detection method for mycotoxins in kelps.

In this work, a rapid, reliable, and sensitive LC-MS/MS method was developed for mycotoxin exposure detection in kelp. In order to obtain a satisfactory recovery for each analyte, sonication and an acidulated extraction pretreatment were investigated and optimized in this work. In order to minimize the matrix effect, each sample was further purified by a PLEXA cartridge. Based on this method, in 43 of 50 kelp samples in Shandong Province, 3AcDON/15AcDON was detected with a positive rate of $86 \%$. In China, Shandong Province is one of the major kelp production and consumption areas, and the contamination of mycotoxins will lead to high dietary exposure risk to human beings.

\section{Results and Discussion}

\subsection{LC-MS/MS Analysis}

The LC isocratic elution program for all 7 compounds could be finished within $7.5 \mathrm{~min}$ and resulted in satisfactory sensitivity and peak shape (Figure 1). From the figure, it is difficult to distinguish $3 \mathrm{AcDON}$ and $15 \mathrm{AcDON}$ from both the chromatogram and spectrum due to the similar structures and same precursor and production ions. Therefore, the two mycotoxins were monitored and calculated as a whole. The optimized MRM parameters are shown in Table 1. The result showed that DON, NIV, and ZEA exhibited higher response in ESI negative mode while $3 \mathrm{AcDON} / 15 \mathrm{AcDON}, \mathrm{F}-\mathrm{X}$, and T-2 toxin exhibited higher response in ESI positive mode, consistent with previous literature [38-40]. 
Table 1. MRM parameters of 7 mycotoxins.

\begin{tabular}{|c|c|c|c|c|c|}
\hline Analyte & Scan Mode & $\begin{array}{l}\text { Precursor Ion } \\
(\mathrm{m} / \mathrm{z})\end{array}$ & $\begin{array}{l}\text { Product Ion } \\
\qquad(m / z)\end{array}$ & $\begin{array}{c}\text { Cone Voltage } \\
\text { (V) }\end{array}$ & $\begin{array}{l}\text { Collision Energy } \\
(\mathrm{eV})\end{array}$ \\
\hline \multirow{4}{*}{$3 \mathrm{AcDON} / 15 \mathrm{AcDON}$} & \multirow{4}{*}{ ESI+ } & \multirow{4}{*}{356.2} & 339.1 & 55.99 & 20.00 \\
\hline & & & $321.2 *$ & 45.00 & 18.73 \\
\hline & & & 230.9 & 55.99 & 23.80 \\
\hline & & & 145.3 & 45.00 & 25.92 \\
\hline \multirow{2}{*}{ DON } & \multirow{2}{*}{$\mathrm{ESI}-$} & \multirow{2}{*}{294.9} & $264.6 *$ & -70.89 & -15.12 \\
\hline & & & 137.9 & -69.02 & -24.18 \\
\hline \multirow{2}{*}{$\mathrm{F}-\mathrm{X}$} & \multirow{2}{*}{ ESI+ } & \multirow{2}{*}{372.2} & $355.0 *$ & 4.87 & 10.78 \\
\hline & & & 247.3 & 7.90 & 19.02 \\
\hline \multirow{2}{*}{ NIV } & \multirow{2}{*}{ ESI- } & \multirow{2}{*}{357.1} & 311.3 & -54.95 & -16.25 \\
\hline & & & $281.3 *$ & -54.95 & -12.90 \\
\hline \multirow{2}{*}{$\mathrm{T}-2$} & \multirow{2}{*}{ ESI+ } & \multirow{2}{*}{489.0} & 327.0 & 20.00 & 245.00 \\
\hline & & & $245.0 *$ & 20.00 & 327.00 \\
\hline \multirow{2}{*}{ ZEA } & \multirow{2}{*}{ ESI- } & \multirow{2}{*}{316.9} & 175.0 & -80.00 & -39.82 \\
\hline & & & $130.9 *$ & -80.00 & -34.62 \\
\hline
\end{tabular}

* (ion for quantification).

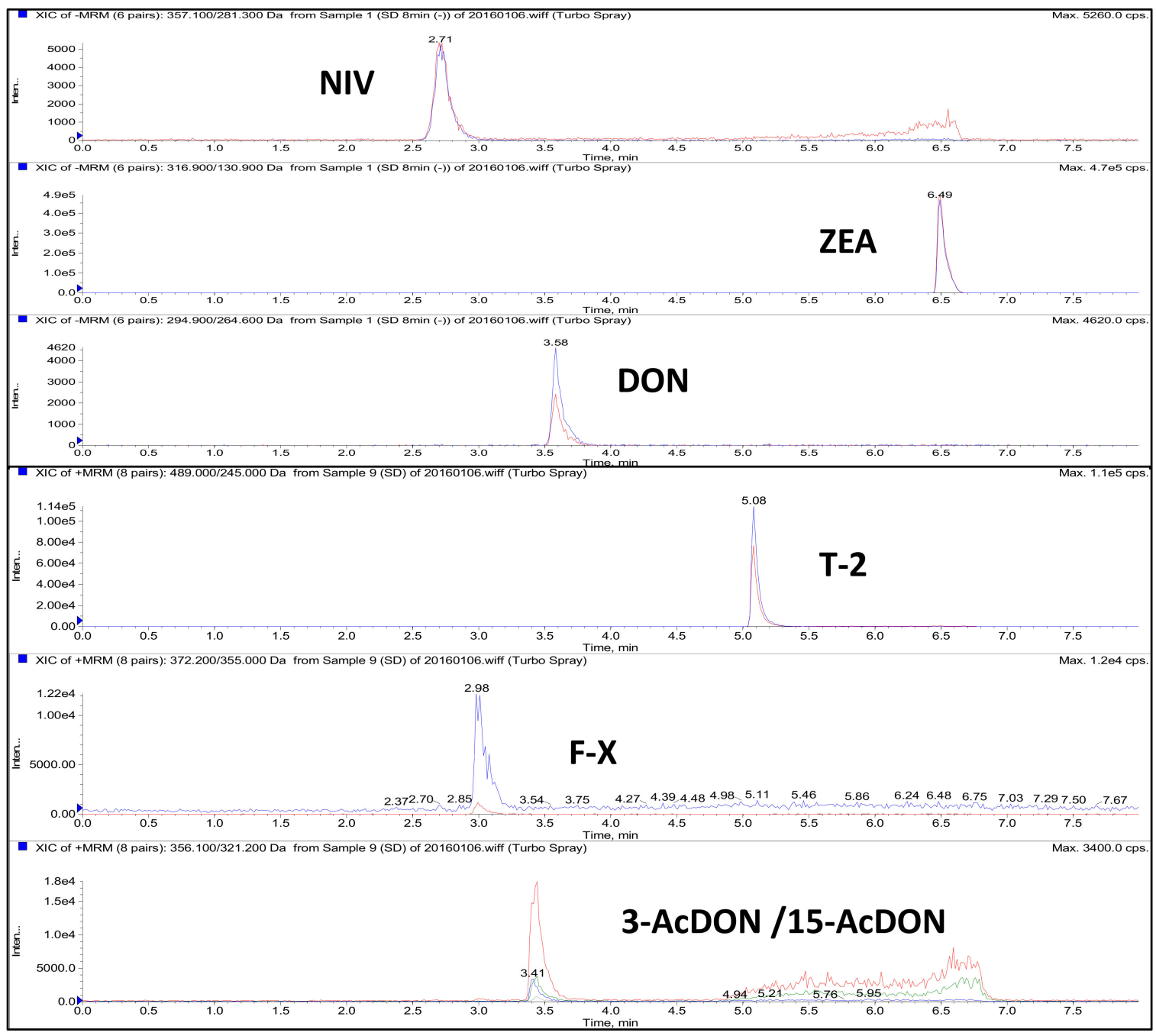

Figure 1. MRM chromatograms of 7 mycotoxins in kelp samples fortified at $50 \mu \mathrm{g} \mathrm{kg}{ }^{-1}$. 


\subsection{Optimization of Sample Preparation}

\subsubsection{Optimization of Extraction Procedure}

Extraction is the first step in the sample preparation process for a satisfactory result. Methanol [41], ethyl acetate [42], acetonitrile and water [43] were adopted as the extraction solvents. For extraction of multiple mycotoxins, the most commonly used is Acetonitrile/water $(84 / 16, v / v)$ [44,45]. According to the previous literature and the structures of these targets, different percentages of solvent were tested for extraction. The results showed that a single solvent (acetonitrile, ethyl acetate, methanol, and water) led to poor recovery for most target compounds. In this research, two combinations of acetonitrile/water $(84 / 16, v / v)$ and methanol/acetonitrile/formic acid $(49.5 / 49.5 / 1, v / v / v)$ were also investigated for extraction evaluation. Recoveries of target compounds applying the two extract solvents are shown in Figure 2.

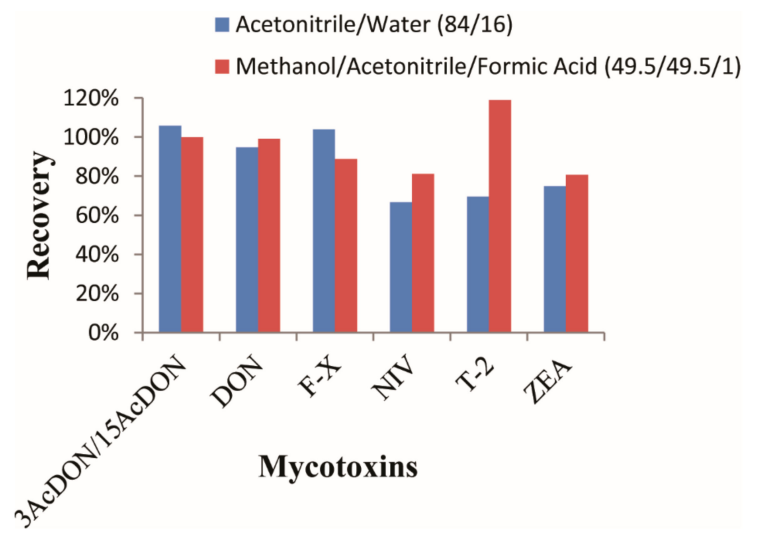

Figure 2. Optimization of extraction efficiency with two different extraction solvents.

From the figure, it could be concluded that recovery with acetonitrile/water $(84 / 16, v / v)$ was better than that with methanol/acetonitrile/formic acid (49.5/49.5/1, $v / v / v)$ for 3AcDON/15AcDON and F-X with recoveries all above $100 \%$. This might be due to the high polarity of the three compounds. For the other mycotoxins, it was observed that methanol/acetonitrile/formic acid led to higher recoveries than acetonitrile/water. Especially for the T-2 toxin, obvious differences in recoveries were obtained between the two extract solvents, with methanol/acetonitrile/formic acid leading to a satisfactory result, while acetonitrile/water leading to a lower recovery. For DON, NIV, and ZEA, methanol/acetonitrile/formic acid exhibited higher recovery than the other solvents. Therefore, methanol/acetonitrile/formic acid $(49.5 / 49.5 / 1, v / v / v)$ was adopted as the extraction solvent for all the seven mycotoxins.

For higher recovery, the extraction conditions were further optimized by sonication extraction time $(1,2,3$, and $4 \mathrm{~min})$, formic acid concentration $(0.5,1,1.5$, and $2 \%)$, and volume of extract solvent $(10,15,20$, and $25 \mathrm{~mL})$ for the extraction of $2 \mathrm{~g}$ of samples. The results are shown in Table 2.

From the table, it could be concluded that the most suitable concentration of formic acid for the extraction of all 7 mycotoxins was $1 \%$. It was observed that $2 \%$ formic acid concentration led to a low concentration of DON, NIV, and ZEA, while $1.5 \%$ led to a low concentration of the T-2 toxin and DON. As for the concentration of formic acid at $0.5 \%$ and $1 \%, 1 \%$ concentration of formic acid led to a slightly better result. Therefore, $1 \%$ formic acid was adopted in this research. For the optimization of sonication, it was observed that $2 \mathrm{~min}$ and $4 \mathrm{~min}$ of sonication led to satisfactory recoveries of all the mycotoxins, while 1 min led to low recoveries of T-2 toxin, F-X, NIV, DON, and ZEA, and 3 min led to low recoveries of T-2 toxin and NIV. In order to simplify the extraction procedure, 2 min sonication time was adopted in this work. As for the volume of extract solvent for the extraction of 2-g samples, it was observed that $20 \mathrm{~mL}$ of extract could lead to satisfactory recoveries for all 7 compounds, while 10 and $15 \mathrm{~mL}$ of extraction solution was not sufficient to extract all the compounds. As for $25 \mathrm{~mL}$ of 
extract, low recoveries were obtained due to rapid loss of targets in the pretreatment process after excessive dilution.

Table 2. Optimization of different extraction conditions.

\begin{tabular}{cccccccc}
\hline \multirow{2}{*}{ Condition } & \multirow{2}{*}{ Parameter } & \multicolumn{7}{c}{ Recovery } \\
\cline { 2 - 7 } & & 3AcDON/15AcDON & T-2 & F-X & NIV & DON & ZEA \\
\hline \multirow{3}{*}{ Formic Acid } & 0.5 & $82 \%$ & $95 \%$ & $78 \%$ & $79 \%$ & $9 \%$ & $91 \%$ \\
$(\%)$ & 1 & $91 \%$ & $90 \%$ & $91 \%$ & $77 \%$ & $94 \%$ & $96 \%$ \\
& 1.5 & $90 \%$ & $72 \%$ & $80 \%$ & $79 \%$ & $90 \%$ & $95 \%$ \\
& 2 & $91 \%$ & $99 \%$ & $86 \%$ & $72 \%$ & $74 \%$ & $77 \%$ \\
\hline \multirow{2}{*}{ Sonication } & 1 & $89 \%$ & $75 \%$ & $80 \%$ & $82 \%$ & $63 \%$ & $74 \%$ \\
$($ min) & 2 & $95 \%$ & $91 \%$ & $90 \%$ & $94 \%$ & $101 \%$ & $81 \%$ \\
& 3 & $95 \%$ & $75 \%$ & $92 \%$ & $82 \%$ & $101 \%$ & $86 \%$ \\
& 4 & $100 \%$ & $90 \%$ & $91 \%$ & $81 \%$ & $99 \%$ & $88 \%$ \\
\hline & 10 & $91 \%$ & $80 \%$ & $90 \%$ & $68 \%$ & $80 \%$ & $93 \%$ \\
Extract Volume & 15 & $98 \%$ & $102 \%$ & $80 \%$ & $70 \%$ & $84 \%$ & $77 \%$ \\
$(\mathrm{~mL})$ & 20 & $102 \%$ & $99 \%$ & $94 \%$ & $84 \%$ & $90 \%$ & $91 \%$ \\
& 25 & $95 \%$ & $101 \%$ & $96 \%$ & $69 \%$ & $95 \%$ & $90 \%$ \\
\hline
\end{tabular}

\subsubsection{Optimization of Purification Procedure}

In the previous, MSPD (matrix solid phase dispersion) [46,47], SPE (Solid Phase Extraction) [48], IAC (Immunoaffinity Colum) [6,11,43], and MycoSep227 [49] were applied for mycotoxin purification. However, MSPD requires a complicated treatment procedure and it is not suitable for high-throughput analysis. IAC requires specific antibodies for the combination of target analytes. Moreover, IAC is usually applied for high-specific and class-specific analysis of targets. It is not suitable for the detection of multiple mycotoxins. Therefore, in this research, SPE cartridges (C18 and PLEXA) were investigated and optimized with different elutions (methanol and acetonitrile) for the purification of the 7 target mycotoxins (Figure 3). From the figure, when acetonitrile was used as the elute solvent, recoveries of DON and F-X were very low. Recoveries of all the targets were satisfactory in both the PLEXA and C18 columns with methanol as the elute solvent. Furthermore, the recoveries of target analytes in the PLEXA column were higher than in the C18 column with methanol as the elute solvent. Therefore, the PLEXA column was adopted for mycotoxins purification with methanol as the elute solvent.

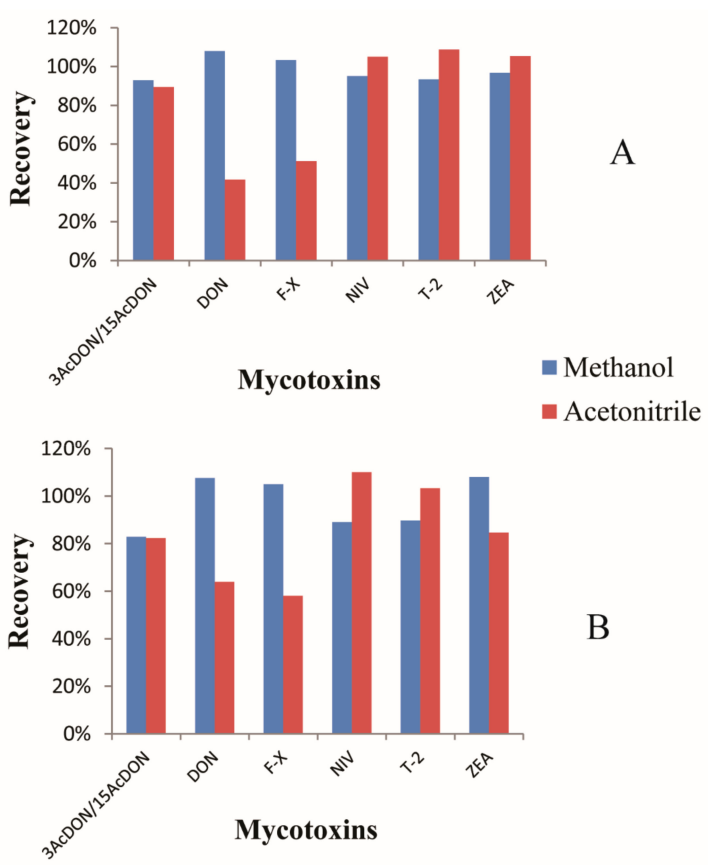

Figure 3. Optimization of the C18 cartridge with Methanol and Acetonitrile as the eluents (A). Optimization of the PLEXA cartridge with Methanol and Acetonitrile as the eluents (B). 


\subsection{Method Validation}

\subsubsection{Linearity}

In order to evaluate the linearity of this procedure, matrix-matched regression calibration curves were investigated at 7 spiked levels from 1 to $1000 \mu \mathrm{g} \mathrm{kg}^{-1}$. The equations for each analyte are shown in Table 3 with correlation coefficients $(r)$ over 0.99 . The wide range can cover the entire target analyte concentrations determined in clinical samples. Samples with high contaminated levels over liner range could be diluted before LC-MS/MS detection

Table 3. Parameters (including the standard curve, LOD, and LOQ) of 7 mycotoxins in kelps.

\begin{tabular}{cccccc}
\hline Analyte & $\begin{array}{c}\text { Liner Range } \\
\left(\mu \mathbf{~ k g}^{-\mathbf{1}}\right)\end{array}$ & $\begin{array}{c}\text { Regression } \\
\text { Equitation }\end{array}$ & $\boldsymbol{r}$ & $\begin{array}{c}\text { LOD } \\
\left(\mu \mathbf{~ k g}^{-1}\right)\end{array}$ & $\begin{array}{c}\mathbf{L O Q} \\
(\boldsymbol{\mu g ~ k g} \mathbf{~ k})\end{array}$ \\
\hline 3AcDON/15AcDON & $1.0-1000$ & $y=17.55 x+5730.2$ & 0.9981 & 3.02 & 10.06 \\
DON & $1.0-1000$ & $y=24.62 x+217.57$ & 0.9994 & 2.6 & 8.68 \\
F-X & $1.0-1000$ & $y=19.84 x+3384.8$ & 0.9902 & 5.55 & 18.5 \\
NIV & $1.0-1000$ & $y=2.016 x+439.40$ & 0.9931 & 1.14 & 3.81 \\
T-2 & $1.0-1000$ & $y=46.75 x+76.992$ & 0.9921 & 0.16 & 0.53 \\
ZEA & $1.0-1000$ & $y=399.4 x+178.21$ & 0.9949 & 0.22 & 0.73 \\
\hline
\end{tabular}

\subsubsection{LOD (Limit of Detection)}

LOD was determined on the basis of the $\mathrm{S} / \mathrm{N}$ ratio higher than 3 in fortified samples, while LOQ (Limit of Quantification) was determined on the basis of the S/N ratio higher than 10. LOD and LOQ achieved in our work were sensitive. LOD was lower than $5.55 \mu \mathrm{g} \mathrm{kg}^{-1}$, while LOQ was lower than $18.5 \mu \mathrm{g} \mathrm{kg}^{-1}$ for all the analytes (Table 3).

\subsubsection{Accuracy and Precision}

Accuracy and precision of this method are shown in Table 4. These values were evaluated from recoveries of each analyte in fortified samples at two different spiked concentrations. Recoveries were determined by the calculated concentrations divided by the spiked levels. The intra-day and inter-day RSDs (Relative Standard Deviations) of each analyte were determined from process fortified samples with each concentration of 5 replicates on three separate days. From the table, mean recoveries were 72.59 107.34\% for all the analytes with intra-day RSD less than $9.21 \%$ and inter-day RSD less than $9.09 \%$, respectively. From the results, it can be concluded that the developed method could be applied to monitor these mycotoxins in kelps.

Table 4. Accuracy and precision of mycotoxins in kelps.

\begin{tabular}{|c|c|c|c|c|c|c|c|c|}
\hline \multirow[b]{2}{*}{ Analyte } & \multirow[b]{2}{*}{$\begin{array}{l}\text { Spiked Level } \\
\quad\left(\mu \mathrm{kg}^{-1}\right)\end{array}$} & \multicolumn{2}{|c|}{ Day 1} & \multicolumn{2}{|l|}{ Day 2} & \multicolumn{2}{|l|}{ Day 3} & \multirow[b]{2}{*}{$\begin{array}{c}\text { Inter-Day } \\
\text { RSD \% } \\
(n=15)\end{array}$} \\
\hline & & $\begin{array}{c}\text { Mean Recovery } \\
(\%)\end{array}$ & $\begin{array}{c}\text { Intra-Day } \\
\text { RSD \% } \\
(n=5)\end{array}$ & $\begin{array}{c}\text { Mean Recovery } \\
(\%)\end{array}$ & $\begin{array}{c}\text { Intra-Day } \\
\text { RSD \% } \\
(n=5)\end{array}$ & $\begin{array}{c}\text { Mean Recovery } \\
(\%)\end{array}$ & $\begin{array}{c}\text { Intra-Day } \\
\text { RSD \% } \\
(n=5)\end{array}$ & \\
\hline \multirow{2}{*}{$3 \mathrm{AcDON} / 15 \mathrm{AcDON}$} & 50 & $90.21 \pm 2.71$ & 2.81 & $91.46 \pm 1.04$ & 1.04 & $93.13 \pm 6.25$ & 5.97 & 3.65 \\
\hline & 100 & $92.59 \pm 9.26$ & 9.17 & $101.5 \pm 8.52$ & 7.77 & $91.11 \pm 8.89$ & 9.21 & 9.09 \\
\hline \multirow{2}{*}{ DON } & 50 & $75.61 \pm 2.05$ & 2.41 & $77.08 \pm 0.58$ & 0.71 & $79.83 \pm 3.26$ & 4.07 & 3.41 \\
\hline & 100 & $101.1 \pm 4.01$ & 3.76 & $101.2 \pm 7.33$ & 7.08 & $104.9 \pm 3.33$ & 3.07 & 4.63 \\
\hline \multirow{2}{*}{$\mathrm{F}-\mathrm{X}$} & 50 & $97.50 \pm 0.83$ & 0.85 & $98.61 \pm 3.06$ & 2.72 & $101.1 \pm 1.94$ & 1.71 & 2.32 \\
\hline & 100 & $98.50 \pm 5.51$ & 5.01 & $94.33 \pm 5.67$ & 5.44 & $93.80 \pm 8.7$ & 8.06 & 5.91 \\
\hline \multirow[b]{2}{*}{ NIV } & 50 & $104.0 \pm 4.63$ & 3.86 & $103.0 \pm 1.67$ & 1.48 & $107.3 \pm 5.65$ & 4.82 & 3.71 \\
\hline & 100 & $93.97 \pm 6.83$ & 6.31 & $93.98 \pm 7.22$ & 6.68 & $99.88 \pm 9.69$ & 9.12 & 7.23 \\
\hline \multirow{2}{*}{$\mathrm{T}-2$} & 50 & $91.23 \pm 6.23$ & 6.45 & $90.00 \pm 5.01$ & 4.84 & $94.37 \pm 2.73$ & 2.72 & 4.73 \\
\hline & 100 & $97.38 \pm 9.76$ & 9.05 & $89.52 \pm 8.09$ & 8.79 & $90.83 \pm 9.4$ & 8.98 & 8.71 \\
\hline \multirow[b]{2}{*}{ ZEA } & 50 & $72.59 \pm 0.74$ & 0.88 & $74.44 \pm 5.22$ & 3.95 & $80.00 \pm 4.44$ & 4.81 & 5.47 \\
\hline & 100 & $86.24 \pm 7.09$ & 7.46 & $77.65 \pm 5.68$ & 6.34 & $77.51 \pm 3.26$ & 3.82 & 7.59 \\
\hline
\end{tabular}




\subsection{Dietary Exposure of Mycotoxins in Kelp}

In order to investigate the dietary exposure of mycotoxins in kelp, 50 kelp samples were obtained from a local supermarket in Shandong Province, China. Each sample was processed according to this LC-MS/MS protocol. In total, 43 kelp samples were detected with 3AcDON/15AcDON, with a positive rate of $86 \%$, while T-2, F-X, DON, ZEA and NIV were negative in all tested samples in Shandong Province in Northern China (Table 5). Considering that the major difference between kelps and cereals is salinity, it seems that the Foodborne fungi can mainly produce acetylated metabolites of DON. As for T-2 toxin, F-X, ZEA, and NIV, they might not be produced in marine food with a high percentage of salinity. It is reported that the kelp production in China accounts for almost $80 \%$ of the whole world. In China, Shandong Province, Fujian Province, and Liaoning Province are the main kelp production regions, which produce about $99 \%$ of the total kelp output, which is over two million tons (Analysis and prospect of kelp industry development in China, 2016-2020). The kelp production in Shandong Province is over 800 thousand tons. The consumption patterns mainly include direct consumption and health product production. However, investigations about mycotoxins in kelp are limited until now. The exposure risk of mycotoxins in kelp dietary is neglected. From the commercial samples tested in this work, it can be concluded that dietary kelp might be a potential exposure pathway of 3AcDON/15AcDON. 
Table 5. Mycotoxin contamination exposure in commercial kelp samples in Shandong Province in Northern China.

\begin{tabular}{|c|c|c|c|c|c|c|c|c|c|c|c|}
\hline No. & $\begin{array}{c}\text { 3AcDON/15AcDON } \\
\left(\mu \mathrm{kg}^{-1}\right)\end{array}$ & $\begin{array}{c}\text { Other Mycotoxins } \\
\left(\mu \mathrm{g} \mathrm{kg}^{-1}\right)\end{array}$ & No. & $\begin{array}{c}\text { 3AcDON/15AcDON } \\
\left(\mu \mathrm{g} \mathrm{kg}^{-1}\right)\end{array}$ & $\begin{array}{l}\text { Other Mycotoxins } \\
\left(\mu \mathrm{g} \mathrm{kg}^{-1}\right)\end{array}$ & No. & $\begin{array}{c}\text { 3AcDON/15AcDON } \\
\left(\mu \mathrm{g} \mathrm{kg}^{-1}\right)\end{array}$ & $\begin{array}{c}\text { Other Mycotoxins } \\
\left(\mu \mathrm{gg}^{-1}\right)\end{array}$ & No. & $\begin{array}{c}\text { 3AcDON/15AcDON } \\
\left(\mu \mathrm{kg}^{-1}\right)\end{array}$ & $\begin{array}{c}\text { Other Mycotoxins } \\
\left(\mu \mathrm{g} \mathrm{kg}^{-1}\right)\end{array}$ \\
\hline 1 & 100 & ND & 14 & 25.6 & ND & 27 & 15.3 & $\mathrm{ND}$ & 40 & 54.8 & ND \\
\hline 2 & 87.5 & ND & 15 & ND & ND & 28 & 19 & ND & 41 & 36.1 & ND \\
\hline 3 & 57.5 & ND & 16 & ND & ND & 29 & ND & $\mathrm{ND}$ & 42 & ND & ND \\
\hline 4 & 75 & ND & 17 & 35.9 & ND & 30 & 39.3 & ND & 43 & 27.4 & ND \\
\hline 5 & 137.5 & ND & 18 & 41.2 & ND & 31 & 42.1 & ND & 44 & 58 & ND \\
\hline 6 & 78.75 & ND & 19 & 31.9 & ND & 32 & ND & $\mathrm{ND}$ & 45 & 37.5 & ND \\
\hline 7 & 106.25 & ND & 20 & 28.5 & ND & 33 & 21.6 & ND & 46 & 55.3 & ND \\
\hline 8 & 77.5 & ND & 21 & 22.5 & ND & 34 & 33.9 & ND & 47 & 46.7 & ND \\
\hline 9 & 162.5 & ND & 22 & ND & ND & 35 & 58.9 & ND & 48 & 43.1 & ND \\
\hline 10 & 87.5 & ND & 23 & 43.8 & ND & 36 & 68.3 & ND & 49 & 28.9 & ND \\
\hline 11 & 118.75 & ND & 24 & 56.7 & ND & 37 & 17.3 & $\mathrm{ND}$ & 50 & 36.2 & ND \\
\hline 12 & 96.3 & ND & 25 & 55.2 & ND & 38 & 22.8 & ND & & & \\
\hline 13 & 33.2 & ND & 26 & 21.6 & ND & 39 & ND & ND & & & \\
\hline
\end{tabular}

Other mycotoxins include DON, F-X, NIV, T-2, and ZEA. 


\section{Conclusions}

In conclusion, a sonication based quantitative and confirmatory LC-MS/MS procedure was developed for the determination of 7 major mycotoxins ( $3 A c D O N, 15 A c D O N, D O N, F-X, N I V, T-2$, and ZEA). Specifically, target analytes were extracted with acidulated methanol/acetonitrile/formic acid $(49.5 / 49.5 / 1, v / v / v)$. After the extraction, each sample was further purified by a PLEXA cartridge to minimize the matrix effect. The validation of this developed procedure proved the suitability of the method for the confirmatory analysis of mycotoxins with mean recoveries from $72.59 \sim 107.34 \%$, intra-day RSD $<9.21 \%$, inter-day RSD $<9.09 \%$, LOD $<5.55 \mu \mathrm{g} \mathrm{kg}-1$, and LOQ $<18.5 \mu \mathrm{g} \mathrm{kg}{ }^{-1}$. With respect to real samples, T-2, F-X, DON, ZEA and NIV were not detected in any sample, while all samples had 3AcDON/15AcDON that ranged from 57.5 to $162.5 \mu \mathrm{g} \mathrm{kg}-1$ with a positive rate of $86 \%$. Considering that Shandong Province is one of the major kelp production and consumption areas in China (over $40 \%$ ), the contamination of mycotoxins will lead to high dietary exposure risk to human beings.

\section{Materials and Methods}

\subsection{Chemicals and Reagents}

3-Acetyldeoxynivalenol (3AcDON), 15-Acetyldeoxynivalenol (15AcDON), Deoxynivalenol (DON), Nivalenol (NIV), T-2 toxin (T-2), and Zearalenone (ZEA) (Figure 4) were obtained from Fermentek Biotechnology (Jerusalem, Israel).

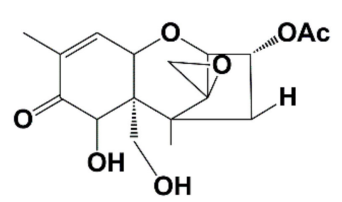

3-Ac-DON

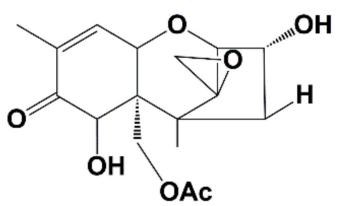

15-Ac-DON

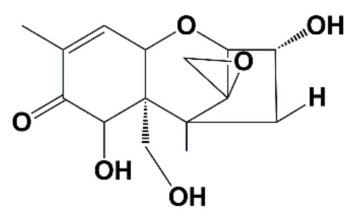

DON

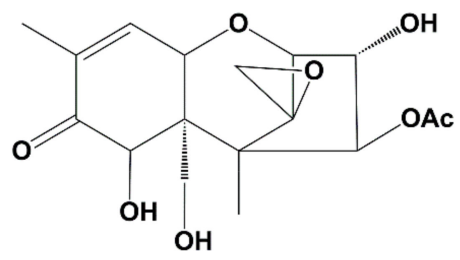

F-X

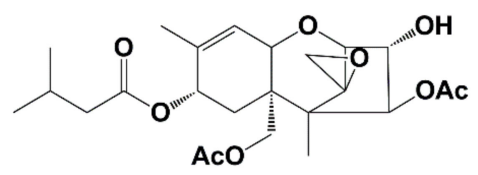

T-2 toxin

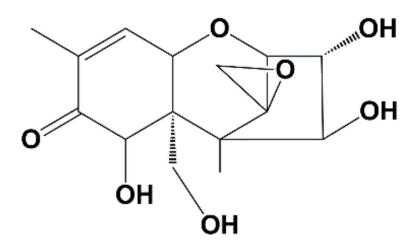

NIV<smiles>CC1CCCC(=O)CCC/C=C/c2cc(O)cc(O)c2C(=O)O1</smiles>

ZEA

Figure 4. Chemical structure of 3-AcDON, 15-AcDON, DON, F-X, NIV, T-2 toxin, and ZEA.

Acetonitrile and methanol (HPLC) were adopted in this work (Dima Technology Inc.) (Muskegon, MI, USA). Formic acid (HPLC) was purchased from Fisher Scientific Inc. (Pittsburgh, PA, USA). Milli-Q Synthesis system (Millipore, Bedford, MA, USA) was used for water purification. Bond Elut PLEXA cartridges $(500 \mathrm{mg}, 6 \mathrm{cc}$ ) (Agilent Technologies, CA, USA) were used 
in this work. Other reagents were obtained from Sinopharm Chemical Reagent Beijing Co., Ltd. (Beijing, China).

\subsection{Apparatus}

The LC system adopted in this research was obtained from AB SCIEX (Redwood City, CA, USA) with a Venusil ASB C18 column $(100 \mathrm{~mm} \times 2.1 \mathrm{~mm}$ i.d., $3 \mu \mathrm{m}$ particle size). The quadrupole mass spectrometer used in this work was a AB4000 triple from AB SCIEX (Redwood, CA, USA). The vortex mixer was from North TZ-Biotech Develop Co., Ltd. (Beijing, China). The N-EVAP 112 nitrogen evaporator was from Organomation Associates (Berlin, MA, USA).

\subsection{Sample Preparation}

Two grams of dried kelp sample was weighed into a 50-mL polypropylene centrifuge tube. Two experiment groups were fortified with 50 and $100 \mu \mathrm{g} \mathrm{kg}{ }^{-1}$ of each analyte. One unfortified group was set as the negative control. Twenty milliliters of methanol/ethyl acetate/formic acid $(49.5 / 49.5 / 1, v / v / v)$ was added and ultrasound was performed for $2 \mathrm{~min}$ followed by vortexing for $3 \mathrm{~min}$ for extraction. Each sample was centrifuged at $9000 \mathrm{rpm}$ for $10 \mathrm{~min}$ at $4{ }^{\circ} \mathrm{C}$. The supernatant was transferred and dried using a nitrogen evaporator at $60^{\circ} \mathrm{C}$. The residues were re-dissolved with $10 \mathrm{~mL}$ of water by vortexing for $3 \mathrm{~min}$. Each sample was loaded onto a PLEXA cartridge with $5 \mathrm{~mL}$ of methanol and $5 \mathrm{~mL}$ of water in turn. After rinsing with $5 \mathrm{~mL}$ of water, analytes were eluted with $5 \mathrm{~mL}$ of methanol. After drying using a nitrogen evaporator at $60^{\circ} \mathrm{C}$, target analytes were re-dissolved with $1 \mathrm{~mL}$ of water/acetonitrile $(9 / 1, v / v)$. Samples were filtered through a $0.22-\mu \mathrm{m}$ filter and $10 \mu \mathrm{L}$ was injected for LC-MS/MS analysis.

\subsection{Instrumental Conditions}

Target analytes were separated via LC system with Venusil ASB C18 column. The mobile phase was as follows: solvent $\mathrm{A}$ (water containing $50 \mu \mathrm{M}$ of ammonium acetate) and solvent B (acetonitrile). The column temperature was set to $25^{\circ} \mathrm{C}$, and the flow rate was $0.5 \mathrm{~mL} \mathrm{~min}{ }^{-1}$ with injection volume of $10 \mu \mathrm{L}$. The gradient elution program was performed for chromatography separation as follows: 0-1 $\mathrm{min}, 98 \%$ A; 1 to $3 \mathrm{~min}, 98-60 \%$ A; 3.0-4.0 $\mathrm{min}, 60 \% \mathrm{~A} ; 4.0-5.0 \mathrm{~min}, 60-10 \% \mathrm{~A} ; 5.0-6.1 \mathrm{~min} 10 \% \mathrm{~A}$; 6.1-6.2 $\min 10-98 \%$ A; $6.2-8.0 \min 98 \%$ A.

For detection, the LC system was coupled to an AB4000 triple quadrupole mass spectrometer (Redwood, CA, USA) with an electrospray ionization source (ESI). For maximum intensity detection, the mass conditions were optimized as follows: Capillary voltage at $5.0 \mathrm{kV}$; Source temperature at $550{ }^{\circ} \mathrm{C}$, IonSpray voltage at $5500 \mathrm{~V}$. Ion Source Gas 1 was 55 Psi, and Ion Source Gas 2 was 55 Psi. The MS instrument was operated in integrate ESI positive (ESI+) and negative (ESI-) multiple reaction monitoring (MRM) mode (Table 1).

Author Contributions: Y.L. and Y.W. conceived and designed the experiment, wrote, and approved the final manuscript; M.S., X.M., and Y.Y. performed the experiment and analyzed the data; Y.G. and J.Y. assisted with the experiment and edited the manuscript.

Funding: This research was funded by the National R\&D Key Programme of China (No. 2017YFE0110800), National Natural Science Foundation of China (Grant No. 31871718), and the EU Horizon 2020 Research and Innovation action (No. 727864-EU-China-Safe).

Conflicts of Interest: The authors declare no conflict of interest. 


\section{References}

1. Oldenburg, E.; Hoppner, F.; Ellner, F.; Weinert, J. Fusarium diseases of maize associated with mycotoxin contamination of agricultural products intended to be used for food and feed. Mycotoxin Res. 2017, 33, 167-182. [CrossRef] [PubMed]

2. Hojnik, N.; Cvelbar, U.; Tavcar-Kalcher, G.; Walsh, J.L.; Krizaj, I. Mycotoxin Decontamination of Food: Cold Atmospheric Pressure Plasma versus “Classic" Decontamination. Toxins (Basel) 2017, 9, 151. [CrossRef] [PubMed]

3. Shephard, G.S. Current Status of Mycotoxin Analysis: A Critical Review. J. AOAC Int. 2016, 99, $842-848$. [CrossRef] [PubMed]

4. Selvaraj, J.N.; Wang, Y.; Zhou, L.; Zhao, Y.; Xing, F.; Dai, X.; Liu, Y. Recent mycotoxin survey data and advanced mycotoxin detection techniques reported from China: A review. Food Addit. Contam. Part A Chem. Anal. Control Expo. Risk Assess. 2015, 32, 440-452. [CrossRef] [PubMed]

5. Stefano, V.; Avellone, G.; Pitonzo, R.; Capocchiano, V.G.; Mazza, A.; Cicero, N.; Dugo, G. Natural co-occurrence of ochratoxin A, ochratoxin B and aflatoxins in Sicilian red wines. Food Addit. Contam. Part A Chem. Anal. Control Expo. Risk Assess. 2015, 32, 1343-1351. [CrossRef] [PubMed]

6. Stefano, V.; Pitonzo, R.; Avellone, G.; Di Fiore, A.; Monte, L.; Ogorka, A.Z.T. Determination of Aflatoxins and Ochratoxins in Sicilian Sweet Wines by High-Performance Liquid Chromatography with Fluorometric Detection and Immunoaffinity Cleanup. Food Anal. Method 2015, 8, 569-577. [CrossRef]

7. Alassane-Kpembi, I.; Kolf-Clauw, M.; Gauthier, T.; Abrami, R.; Abiola, F.A.; Oswald, I.P.; Puel, O. New insights into mycotoxin mixtures: The toxicity of low doses of Type B trichothecenes on intestinal epithelial cells is synergistic. Toxicol. Appl. Pharmacol. 2013, 272, 191-198. [CrossRef] [PubMed]

8. Halenar, M.; Medvedova, M.; Maruniakova, N.; Kolesarova, A.J. Assessment of a potential preventive ability of amygdalin in mycotoxin-induced ovarian toxicity. Environ. Sci. Health B 2015, 50, 411-416. [CrossRef] [PubMed]

9. Jackson, C.; Salomaki, E.D.; Lane, C.E.; Saunders, G.W. Kelp transcriptomes provide robust support for interfamilial relationships and revision of the little known Arthrothamnaceae (Laminariales). J. Phycol. 2017, 53, 1-6. [CrossRef] [PubMed]

10. Pereira, M.; Tala, F.; Fernandez, M.; Subida, M.D. Effects of kelp phenolic compounds on the feeding-Associated mobility of the herbivore snail Tegula tridentata. Mar. Environ. Res. 2015, 112, 40-47. [CrossRef] [PubMed]

11. Irakli, M.N.; Skendi, A.; Papageorgiou, M.D. HPLC-DAD-FLD Method for Simultaneous Determination of Mycotoxins in Wheat Bran. J. Chromatogr. Sci. 2017, 55, 690-696. [CrossRef] [PubMed]

12. Chen, F.; Luan, C.; Wang, L.; Wang, S.; Shao, L. Simultaneous determination of six mycotoxins in peanut by high-performance liquid chromatography with a fluorescence detector. J. Sci. Food Agric. 2017, 97, 1805-1810. [CrossRef] [PubMed]

13. Fan, C.; Cao, X.; Liu, M.; Wang, W. Determination of Alternaria mycotoxins in wine and juice using ionic liquid modified countercurrent chromatography as a pretreatment method followed by high-performance liquid chromatography. J. Chromatogr. A 2016, 1436, 133-140. [CrossRef] [PubMed]

14. Bartok, T.; Szecsi, A.; Juhasz, K.; Bartok, M.; Mesterhazy, A. ESI-MS and MS/MS identification of the first ceramide analogues of fumonisin $\mathrm{B}(1)$ mycotoxin from a Fusarium verticillioides culture following RP-HPLC separation. Food Addit. Contam. Part A Chem. Anal. Control Expo. Risk Assess. 2013, 30, 1651-1659. [CrossRef] [PubMed]

15. Hovelmann, Y.; Hickert, S.; Cramer, B.; Humpf, H.U. Determination of Exposure to the Alternaria Mycotoxin Tenuazonic Acid and Its Isomer allo-Tenuazonic Acid in a German Population by Stable Isotope Dilution HPLC-MS $\left({ }^{3}\right)$. J. Agric. Food Chem. 2016, 64, 6641-6647. [CrossRef] [PubMed]

16. Hickert, S.; Gerding, J.; Ncube, E.; Hubner, F.; Flett, B.; Cramer, B.; Humpf, H.U. A new approach using micro HPLC-MS/MS for multi-mycotoxin analysis in maize samples. Mycotoxin Res. 2015, 31, 109-115. [CrossRef] [PubMed]

17. Valle-Algarra, F.M.; Mateo, E.M.; Mateo, R.; Gimeno-Adelantado, J.V.; Jimenez, M. Determination of type A and type B trichothecenes in paprika and chili pepper using LC-triple quadrupole-MS and GC-ECD. Talanta 2011, 84, 1112-1117. [CrossRef] [PubMed] 
18. Vettorazzi, A.; Gonzalez-Penas, E.; Cerain, A.L. Ochratoxin A kinetics: A review of analytical methods and studies in rat model. Food Chem. Toxicol. 2014, 72, 273-288. [CrossRef] [PubMed]

19. Rodriguez-Carrasco, Y.; Molto, J.C.; Manes, J.; Berrada, H. Development of microextraction techniques in combination with GC-MS/MS for the determination of mycotoxins and metabolites in human urine. J. Sep. Sci. 2017, 40, 1572-1582. [CrossRef] [PubMed]

20. Escriva, L.; Manyes, L.; Font, G.; Berrada, H. Analysis of trichothecenes in laboratory rat feed by gas chromatography-tandem mass spectrometry. Food Addit. Contam. Part A Chem. Anal. Control Expo. Risk Assess. 2016, 33, 329-338. [CrossRef] [PubMed]

21. Rodriguez-Carrasco, Y.; Molto, J.C.; Manes, J.; Berrada, H. Exposure assessment approach through mycotoxin/creatinine ratio evaluation in urine by GC-MS/MS. Food Chem. Toxicol. 2014, 72, 69-75. [CrossRef] [PubMed]

22. Rodriguez-Carrasco, Y.; Molto, J.C.; Manes, J.; Berrada, H. Development of a GC-MS/MS strategy to determine 15 mycotoxins and metabolites in human urine. Talanta 2014, 128, 125-131. [CrossRef] [PubMed]

23. Roman, B.E.; Driksna, D.; Abouzied, M.M.; Klein, F.; Rice, J. Validation of MAX Aqueous Extraction on Veratox(R) for Total Aflatoxin ELISA Test Kit. J. AOAC Int. 2017, 100, 1131-1133. [CrossRef] [PubMed]

24. Righetti, L.; Galaverna, G.; Dall'Asta, C. Group detection of DON and its modified forms by an ELISA kit. Food Addit. Contam. Part A Chem. Anal. Control Expo. Risk Assess. 2017, 34, 248-254. [CrossRef] [PubMed]

25. Kalayu, Y.S.; Ling, S.; Yang, Y.; Yuan, J.; Wang, S. The Preparation and Identification of a Monoclonal Antibody against Citrinin and the Development of Detection via Indirect Competitive ELISA. Toxins (Basel) 2017, 9, 110. [CrossRef] [PubMed]

26. Nasir, M.S.; Jolley, M.E. Fluorescence polarization (FP) assays for the determination of grain mycotoxins (fumonisins, DON vomitoxin and aflatoxins). Comb. Chem. High Throughput Screen 2003, 6, 267-273. [CrossRef] [PubMed]

27. Maragos, C.M. Fluorescence polarization for mycotoxin determination. Mycotoxin Res. 2006, 22, 96-99. [CrossRef] [PubMed]

28. Beloglazova, N.V.; Eremin, S.A. Rapid screening of aflatoxin B1 in beer by fluorescence polarization immunoassay. Talanta 2015, 142, 170-175. [CrossRef] [PubMed]

29. Joshi, S.; Segarra-Fas, A.; Peters, J.; Zuilhof, H.; Van Beek, M.W.; Nielen, T.A. Multiplex surface plasmon resonance biosensing and its transferability towards imaging nanoplasmonics for detection of mycotoxins in barley. Analyst 2016, 141, 1307-1318. [CrossRef] [PubMed]

30. Zhu, Z.; Feng, M.; Zuo, L.; Zhu, Z.; Wang, F.; Chen, L.; Li, J.; Shan, G.; Luo, S.Z. An aptamer based surface plasmon resonance biosensor for the detection of ochratoxin A in wine and peanut oil. Biosens. Bioelectron. 2015, 65, 320-326. [CrossRef] [PubMed]

31. Joshi, S.; Zuilhof, H.; Van Beek, T.A.; Nielen, M.W. Biochip Spray: Simplified Coupling of Surface Plasmon Resonance Biosensing and Mass Spectrometry. Anal. Chem. 2017, 89, 1427-1432. [CrossRef] [PubMed]

32. Park, J.H.; Byun, J.Y.; Mun, H.; Shim, W.B.; Shin, Y.B.; Li, T.; Kim, M.G. A regeneratable, label-free, localized surface plasmon resonance (LSPR) aptasensor for the detection of ochratoxin A. Biosens. Bioelectron. 2014, 59, 321-327. [CrossRef] [PubMed]

33. Peters, J.; Bienenmann-Ploum, M.; De Rijk, T.; Haasnoot, W. Development of a multiplex flow cytometric microsphere immunoassay for mycotoxins and evaluation of its application in feed. Mycotoxin Res. 2011, 27, 63-72. [CrossRef] [PubMed]

34. Deng, G.; Xu, K.; Sun, Y.; Chen, Y.; Zheng, T.; Li, J. High sensitive immunoassay for multiplex mycotoxin detection with photonic crystal microsphere suspension array. Anal. Chem. 2013, 85, 2833-2840. [CrossRef] [PubMed]

35. Xu, K.; Sun, Y.; Li, W.; Xu, J.; Cao, B.; Jiang, Y.; Zheng, T.; Li, J.; Pan, D. Multiplex chemiluminescent immunoassay for screening of mycotoxins using photonic crystal microsphere suspension array. Analyst 2014, 139, 771-777. [CrossRef] [PubMed]

36. Yao, J.; Sun, Y.; Li, Q.; Wang, F.; Teng, M.; Yang, Y.; Deng, R.; Hu, X. Colloidal gold-McAb probe-based rapid immunoassay strip for simultaneous detection of fumonisins in maize. J. Sci. Food Agric. 2017, 97, 2223-2229. [CrossRef] [PubMed]

37. Shiu, C.M.; Wang, J.J.; Yu, F.Y. Sensitive enzyme-linked immunosorbent assay and rapid one-step immunochromatographic strip for fumonisin B1 in grain-based food and feed samples. J. Sci. Food Agric. 2010, 90, 1020-1026. [CrossRef] [PubMed] 
38. Zhang, K.; Schaab, M.R.; Southwood, G.; Tor, E.R.; Aston, L.S.; Song, W.; Eitzer, B.; Majumdar, S.; Lapainis, T.; Mai, H.; et al. A Collaborative Study: Determination of Mycotoxins in Corn, Peanut Butter, and Wheat Flour Using Stable Isotope Dilution Assay (SIDA) and Liquid Chromatography-Tandem Mass Spectrometry (LC-MS/MS). J. Agric. Food Chem. 2017, 65, 7138-7152. [CrossRef] [PubMed]

39. Thanner, S.; Czegledi, L.; Schwartz-Zimmermann, H.E.; Berthiller, F.; Gutzwiller, A. Urinary deoxynivalenol (DON) and zearalenone (ZEA) as biomarkers of DON and ZEA exposure of pigs. Mycotoxin Res. 2016, 32, 69-75. [CrossRef] [PubMed]

40. Flores-Flores, M.E.; Gonzalez-Penas, E. Development and validation of a high performance liquid chromatographic-mass spectrometry method for the simultaneous quantification of 10 trichothecenes in ultra-high temperature processed cow milk. J. Chromatogr. A 2015, 1419, 37-44. [CrossRef] [PubMed]

41. Boutsiadou-Theurillat, X.; Meier, P.; Richard, C. Development and in-house Validation of a Rapid LC-MS/MS Method for the Semi-quantification of Eleven Mycotoxins in Maize Samples. Chimia 2014, 68, 716-720. [CrossRef] [PubMed]

42. Li, S.; Li, Y.; Wang, Y.; Zhou, W.; Gao, H.; Zhang, S. Water-based slow injection ultrasound-assisted emulsification microextraction for the determination of deoxynivalenol and de-epoxy-deoxynivalenol in maize and pork samples. Anal. Bioanal. Chem. 2013, 405, 4307-4311. [CrossRef] [PubMed]

43. Li, Y.; Wang, Z.; Saeger, S.; Shi, W.; Li, C.; Zhang, S.; Cao, X.; Shen, J. Determination of deoxynivalenol in cereals by immunoaffinity clean-up and ultra-high performance liquid chromatography tandem mass spectrometry. Methods 2012, 56, 192-197. [CrossRef] [PubMed]

44. Juan, C.; Ritieni, A.; Manes, J. Determination of trichothecenes and zearalenones in grain cereal, flour and bread by liquid chromatography tandem mass spectrometry. Food Chem. 2012, 134, 2389-2397. [CrossRef] [PubMed]

45. Li, Y.; Wang, Z.; Beier, R.C.; Shen, J.; Smet, D.D.; Saeger, S.; Zhang, S. T-2 toxin, a trichothecene mycotoxin: Review of toxicity, metabolism, and analytical methods. J. Agric. Food Chem. 2011, 59, 3441-3453. [CrossRef] [PubMed]

46. Rubert, J.; Soler, C.; Manes, J. Evaluation of matrix solid-phase dispersion (MSPD) extraction for multi-mycotoxin determination in different flours using LC-MS/MS. Talanta 2011, 85, 206-215. [CrossRef] [PubMed]

47. Zhu, R.; Zhao, Z.; Wang, J.; Bai, B.; Wu, A.; Yan, L.; Song, S. A simple sample pretreatment method for multi-mycotoxin determination in eggs by liquid chromatography tandem mass spectrometry. J. Chromatogr. A 2015, 1417, 1-7. [CrossRef] [PubMed]

48. Wang, M.; Jiang, N.; Xian, H.; Wei, D.; Shi, L.; Feng, X. A single-step solid phase extraction for the simultaneous determination of 8 mycotoxins in fruits by ultra-high performance liquid chromatography tandem mass spectrometry. J. Chromatogr. A 2016, 1429, 22-29. [CrossRef] [PubMed]

49. Bernhardt, K.; Valenta, H.; Kersten, S.; Humpf, H.U.; Danicke, S. Determination of T-2 toxin, HT-2 toxin, and three other type A trichothecenes in layer feed by high-performance liquid chromatography-tandem mass spectrometry (LC-MS/MS)-Comparison of two sample preparation methods. Mycotoxin Res. 2016, 32, 89-97. [CrossRef] [PubMed]

(C) 2018 by the authors. Licensee MDPI, Basel, Switzerland. This article is an open access article distributed under the terms and conditions of the Creative Commons Attribution (CC BY) license (http://creativecommons.org/licenses/by/4.0/). 